\title{
An Innovative Model of Economic Development of the Market
}

\author{
Ayna Salamova* \\ Chechen State University, 364024 Grozny, Russia
}

\begin{abstract}
The transformation of the economy into an innovative socioeconomic system is the basis for fundamental changes in the modern world, radically changing both the nature of labor and the main productive forces, and the appearance of society, the level and quality of its life. The content of the transition of the economy to a new stage of development is such processes as a change in the technological basis and model of economic management, strengthening of its social orientation and, finally, globalization. A fundamentally new technological basis of society is being formed today, a key role in which is played by information computer systems, nano- and biotechnologies, which have an innovative character and dynamism as their distinctive feature. The ongoing intensive development of the needs of society, science, technology, information determines both the expansion of the diversity of existing factors and models of economic growth, and the emergence of new ones.
\end{abstract}

\section{Introduction}

According to the majority of modern researchers-economists, the ongoing innovative transformations not only transform the productive forces of society, but also represent the central link in the system of socio-economic processes. Therefore, in the modern period of rapid development of productive forces, innovations are the main driving force of the dynamic development of social production. According to the concepts of innovative development, each new generation of innovations in engineering and technology expands its sphere of influence in social life. Moreover, self-organization of a person, improving the quality of life in a post-industrial society is directly related to the possibilities of technological renewal. [2]. It is necessary to agree with the opinion of V.G. Zinova, that in the competitive struggle there is competition not so much for the possession of capital resources and material values, but for the ability to develop and implement innovations. The accelerated and largescale development of new technologies leads to the fact that worldwide economic growth is more and more determined by the share of products and equipment that contains progressive knowledge and modern solutions (Fig. 1) [2].

\footnotetext{
*Corresponding author: salamova_chgu@mail.ru
} 


\section{The Concept of "Innovation"}

The concept of "innovation" refers to a new product or service, a method of production, an innovation in organizational, research and other areas, any improvement that provides cost savings or creates conditions for such savings. Most researchers consider innovation to be a set of technical, industrial and commercial activities that lead to the emergence of new products, processes and equipment. Summarizing the etymology of this concept in economic science, we characterize innovation as the use in a particular sphere of society of the results of intellectual activity aimed at improving the processes of activity or its results. Innovations can relate to the spheres of production, economic, legal, social relations, the field of science, culture, education and other spheres of society. This term can have different meanings in different contexts, and their choice depends on the specific goals and directions of the analysis. For a deeper disclosure of the category of "innovation", a systematic approach should be used from the perspective of goal setting and development. The journal "Innovations" gives a generalizing definition of it as a process of implementing a new idea in any area of human life and activity, contributing to the satisfaction of existing needs in the market and bringing economic benefits [3]. According to Rosstat, the situation in the economy of the Russian Federation can be presented in the form of the following table (See Table 1). The leaders are countries with high tech production in full volume [6]. Thus, the current stage of socio-economic development is characterized by the instability of the external environment, increasing competition between market agents, and a reduction in the life cycle of goods and services. That is why the general trend of world economic development is aimed at accelerating the processes of new industrialization, the defining vector of which is systemic innovative development and the formation of high-tech industries both on the scale of national economies and within individual regions. The national high-tech status can be determined by most of the known signs as catching up. In these conditions, the priority of the development of high-tech industries and areas of activity is the restoration of permitted and the formation of new links in the external and internal innovation environment [3].

Table 1. Economy of the leading countries of the world and Russia in 2020

\begin{tabular}{|l|c|c|c|}
\hline & $\begin{array}{c}\text { GDP } \\
\text { (trillion dollars) }\end{array}$ & $\begin{array}{c}\text { GNI per capita } \\
\text { (thousand dollars) }\end{array}$ & $\begin{array}{c}\text { Average income of } \\
\text { the population } \\
\text { (USD) }\end{array}$ \\
\hline Germany & 3,5 & 49770 & 3192 \\
\hline USA & 18,5 & 58030 & 5013 \\
\hline United Kingdom & 2,6 & 42100 & 2845 \\
\hline Japan & 4,9 & 42890 & 2823 \\
\hline China & 11,2 & 15500 & 606 \\
\hline Russia & 1,2 & 22540 & 539 \\
\hline
\end{tabular}

\section{An Innovative Model of the National Economy}

Innovative industries are strategic priorities in the context of the implementation of an innovative model for the development of the national economy of Russia, which are part of science-intensive industries, as the basis for innovative activities of enterprises. In this regard, the state innovation policy pays significant attention to the activation of innovation in science-intensive industries. At the same time, the innovation policy takes into account a wide range of forms and instruments of favorable conditions for the creation and use of technological innovations [10]. 
As a rule, the political and economic category of innovation is, first of all, economic relations arising between citizens, firms, financial institutions regarding the creation and implementation of new technologies and new products in a changing market environment by attracting their own or borrowed funds.

The modern model of economic growth is distinguished, firstly, by consumer orientation, and secondly, by the expression of many of its principles and approaches in strategic management actions aimed at high return on investment. From the point of view of the ratio of the quantity and quality of economic growth, it is customary to distinguish between extensive and intensive models of economic growth [4].

The meaning of the first model is that an increase in the volume of production of goods and services occurs by involving additional production factors of the same quality into the economy. In this case, the main source of economic growth is the increase in the costs of living and materialized labor. The second model is more complex than the first, it is based on resource conservation and comprehensive savings. The source of economic growth here are innovations in technology, organization, management, the result of which is a significant increase in labor productivity and product quality. This growth model is more efficient and competitive. Due to the unevenness of scientific and technological progress in various sectors and spheres of the economy, in real life, extensive and intensive models of economic growth coexist, complementing and developing each other. The ratio of these models of economic growth is different in different countries. But the transformation process that began in the middle of the 20th century objectively turns the resource-saving model of economic growth into a priority one, since only it can provide both a high quality of life and sustainable competitiveness of the industrial economy, first into a post-industrial one, and now into an innovative one.

It seems that "economic growth" is a synthetic concept that is formed as a result of the influence on the development of the economy of both external and internal factors [1], it is characterized by the superiority of the consumer over the producer, the human factor over physical capital and natural resources, the service sector over the sphere material production, information and innovative technologies over production, quality over quantity, flexibility over stability, external environment over internal, world socio-economic standards over national, private sector over state, individual needs over mass, partnership over rivalry [2]. World experience shows that in order to move to a new quality of growth, not separate measures are required, but the complex use of a complex set of diverse factors, the interconnection of which with indicators of economic growth generate its various models. In theory and practice, varieties of economic growth models are known that reflect a particular stage of economic development. Let's consider how such models were modified in the process of development of economic science.

\section{History of Creating Models of Economic Growth}

The first attempt in the field of creating models of economic growth was made by François Kane, who was the first in economic science to balance the natural and material elements of production. The transition to industrial methods of creating and processing products required a different model of economic development, presented by Karl Marx, who recreated the scheme of reproduction, where social production was modeled by two divisions: the production of means of production and the production of consumer goods.

The next step in creating models of economic growth is associated with the names of $\mathrm{V}$. Leontiev and G. Feldman and the method of input-output analysis developed by them, respectively, and a number of new technical and economic coefficients explaining the influence on growth of various types of investment distribution between industries producing capital and consumer goods. At a higher level, the scientific discovery made by G. Feldman 
was repeated two decades later by R. Harrod and E. Domar. E. Domar's model is based on a production function, the factors of which are not interchangeable. The model shows that, firstly, it is necessary to increase the growth of investment to fully utilize the growing production capacities to maintain the equilibrium growth rate at a constant level, and secondly, there is a growth rate that ensures a more complete use of the production potential, which is called guaranteed and is equilibrium. R. Harrod's model shows that to ensure economic growth it is necessary that the saving rate be equal to the product of capital intensity and population growth in the current period [4].

In the following years, the ranks of economic growth theorists were joined by famous names. Among them are such outstanding representatives of post-Keynesianism as J. Robinson and N. Kaldor, the Marxist trend - M. Kaletsky, neoclassical orthodoxy - P. Samuelson, R. Solow, H. Uzawa, H. Khan, and many others. Each of them made a certain contribution to the theory of economic growth, but it was a reaction to what was done by the first three (G. Feldman, R. Harrod and E. Domar). In economic theory, the concept of the "production function" of Cobb-Douglas, which expresses the dependence between output and the factors providing it, has become widely known; among the latter, decisive importance is attached not to labor, but to capital. The Cobb - Douglas model has been adopted by many theorists of economic growth, including the one used in the model of R. Solow, according to which an increase in savings leads in the short term to an increase in capital stocks and to an increase in production until macroeconomic equilibrium is reached at a stable level of capitallabor ratio.

In the long run, production growth depends on the rate of scientific and technological progress. By introducing a new indicator - the rate of technical progress - the Cobb-Douglas production function was improved by J. Tinbergen, whose merit is the calculation of the contribution of technical progress to the rate of economic growth. Without diminishing the importance of the above models of economic growth in macroeconomic regulation, it should be noted that they take into account the influence of only internal factors on economic growth [6]. In the context of globalization of the world economy, countries are moving to a model of an open economy, within which the key factors of its growth are changing and human capital and innovation come to the fore.

Innovation, being a form of manifestation of scientific and technological progress, is a special type of knowledge and the result of the integration of scientific, material and material and personnel potential. Developing, on the one hand, as a single integrated system, science and technology perform completely specific functions and are interconnected with each other. Scientific research creates a potential that materializes in technology and technology that make up the material and technical basis of economic growth, while the effectiveness of both potential is determined by the professionalism and competence of human resources [3, 4].

\section{Conclusions}

1. Given the reproductive nature of economic activity, innovative economic growth must be accompanied by the creation of the necessary sources for future economic growth.

2. To this end, it is necessary to replenish the fund for technological and product innovations, accumulate development budgets while maintaining guarantees of financing the traditional obligations of the state, ensure the growth of the competitive potential of domestic enterprises, the availability of infrastructure services reserves and the growth of induced investments.

3. However, there is a need for a more specific assessment of the conditions and mobilization of additional factors of innovative economic growth. 
4. It is required to activate the state policy to create a favorable business climate and increase the economic activity of the population.

\section{References}

1. A. A. Urunov, Integration and economic growth, 424 (2013)

2. A. V. Balabanova, Macroeconomics, Growth quality improvement mechanisms, 373 (2018)

3. E. V. Ogurtsova, O. Yu. Chelnokova, Economic integration and economic growth: interrelation and interdependence of processes, 3 (2020)

4. O. Yu. Chelnokova, A. A. Firsova, Typology of approaches to the analysis of the influence of the university on innovation development of the region, 578 (2013)

5. Yu. V. Sharaev, Theory of economic growth, 254 (2018)

6. V.G. Zinov, Innovation management: staffing, 11 (2020)

7. F.F. Bezdudny, G.A. Smirnova, O.D. Nechaeva, The essence of the concept of "innovation" and its classification, 13 (2018)

8. S.Yu. Glazyev, The theory of long-term technical and economic development, 5 (2018)

9. Contours of innovative development of the world economy, 70 (2020)

10. B. Kuzyk, Russia - 2050: a strategy for an innovative breakthrough, 474 (2019) 